\title{
STATE OF THE CLIMATE IN 2019
}

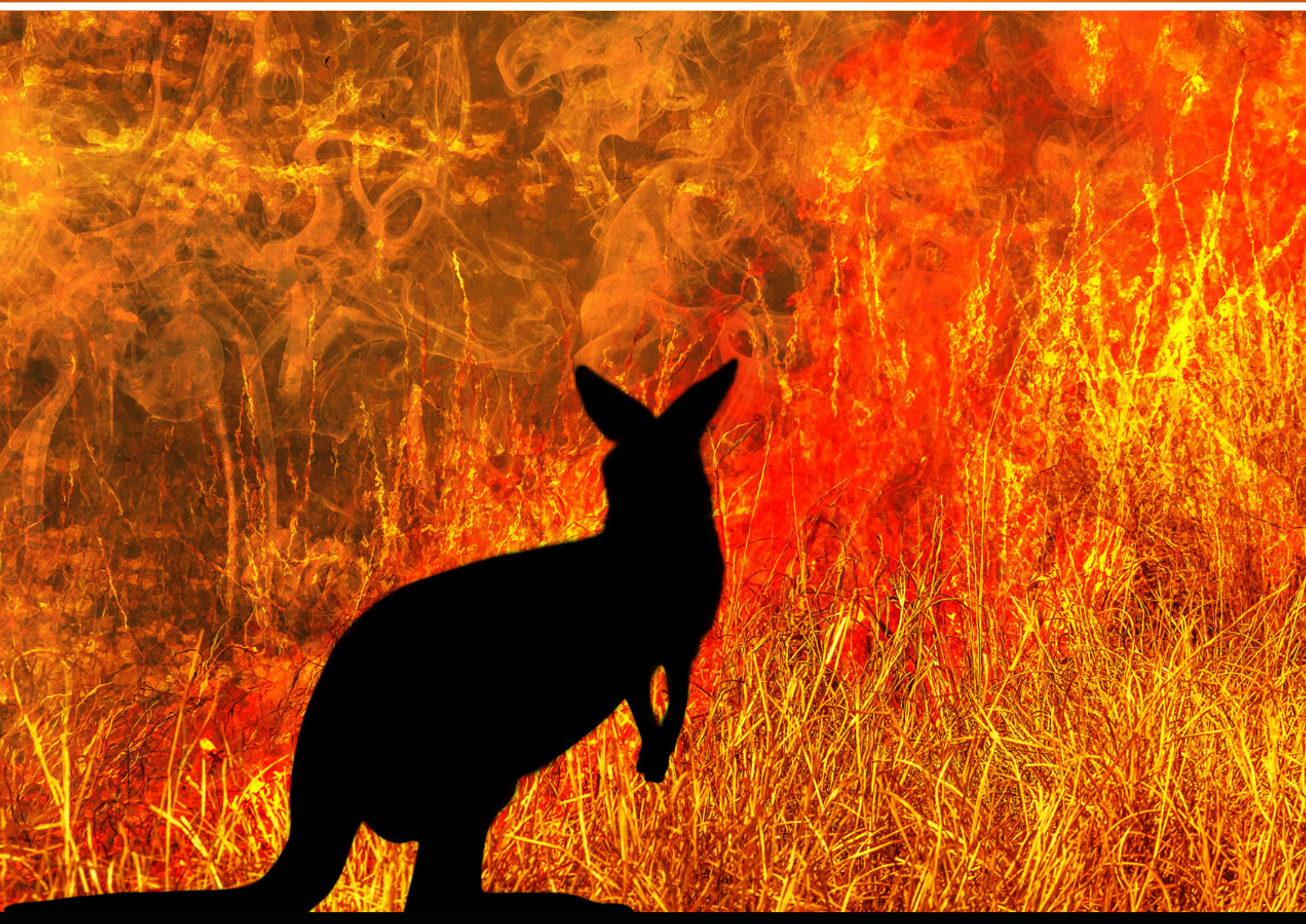

Special Supplement to the Bulletin of the American Meteorological Society Vol. 101, No. 8, August 2020 
Cover credit: Kangaroo silhouette looking a fire in Australia forests. Australian wildlife in bushfires 2019 and 2020. Credit: Benny Marty iStock/Getty Images Plus; Location: Australia/via Getty Images

How to cite this document:

Citing the complete report:

Blunden, J. and D. S. Arndt, Eds., 2020: State of the Climate in 2019. Bull. Amer. Meteor. Soc., 101 (8), Si-S429 https://doi.org/10.1175/2020BAMSStateoftheClimate.1

Special Online Supplement to the Bulletin of the American Meteorological Society, Vol.101, No. 8, August, 2020

https://doi.org/10.1175/2020BAMSStateoftheClimate.1 Corresponding author: Full report: Jessica Blunden / jessica.blunden@noaa.gov @2020 American Meteorological Society For information regarding reuse of this content and general copyright information, consult the AMS Copyright Policy. 


\section{STATE OF THE CLIMATE IN 2019 TABLE OF CONTENTS}

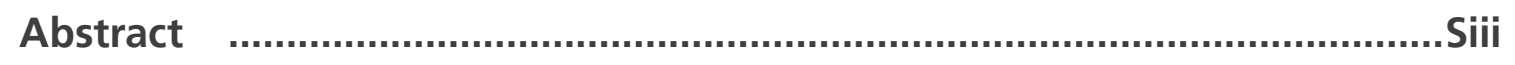

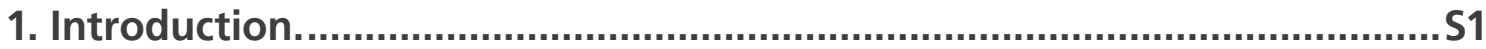

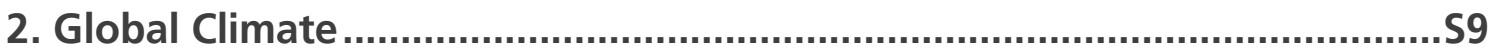

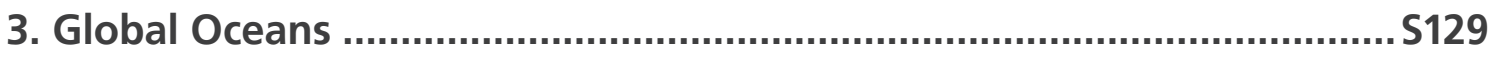

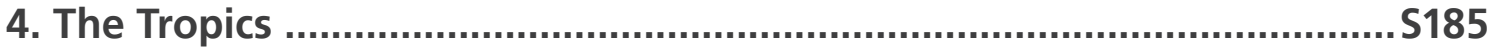

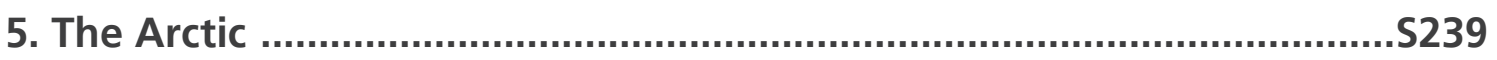

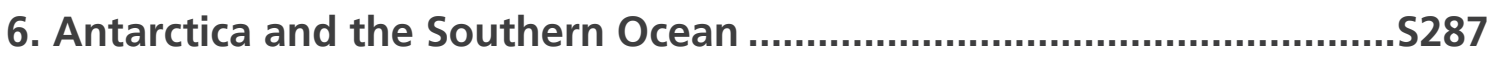

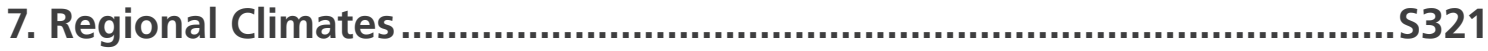

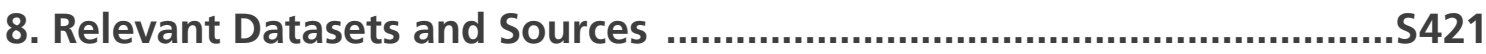




\section{ABSTRACT—J. BLUNDEN AND D. S. ARNDT}

In 2019, the dominant greenhouse gases released into Earth's atmosphere continued to increase. The annual global average carbon dioxide concentration at Earth's surface was $409.8 \pm 0.1 \mathrm{ppm}$, an increase of $2.5 \pm 0.1 \mathrm{ppm}$ over 2018, and the highest in the modern instrumental record and in ice core records dating back 800000 years. Combined, greenhouse gases and several halogenated gases contributed $3.14 \mathrm{~W} \mathrm{~m}^{-2}$ to radiative forcing, representing a $45 \%$ increase since 1990 . Carbon dioxide is responsible for about $65 \%$ of this radiative forcing. The annual net global uptake of $\sim 2.4$ billion metric tons of carbon dioxide by oceans was the highest in the record dating to 1982 and 33\% higher than the 1997-2017 average.

A weak El Niño at the beginning of 2019 transitioned to ENSO-neutral conditions by mid-year. Even so, the annual global surface temperature across land and oceans was still among the three highest in records dating to the mid- to late 1800s. July 2019 was Earth's hottest month on record. Well over a dozen countries across Africa, Europe, Asia, Australia, and the Caribbean reported record high annual temperatures. In North America, Alaska experienced its warmest year on record, while the high northern latitudes that encompass the Arctic were second warmest, behind only 2016. Stations in several countries, including Vietnam, the Netherlands, Belgium, Luxembourg, France, and the United Kingdom, set new all-time daily high temperature records for their nations. Australia set a new nationally averaged daily maximum temperature record of $41.9^{\circ} \mathrm{C}$ on 18 December, breaking the previous record set in 2013 by $1.6^{\circ} \mathrm{C}$. Daily temperatures surpassed $40^{\circ} \mathrm{C}$ for the first time in Belgium and the Netherlands.

Lake temperatures increased on average across the globe in 2019; observed lakes in the Northern Hemisphere were covered in ice seven days fewer than the 1981-2010 average, according to phenological indicators. Over land, the growing season was an average of eight days longer than the 2000-10 average in the $\mathrm{NH}$.

Above Earth's surface, the annual lower troposphere temperature was third highest to record high, and the lower stratosphere temperature was third lowest to record low, depending on the dataset analyzed. Middle- and upper-stratospheric temperatures were lowest on record since satellite records began in 1979. In September, Antarctica experienced a dramatic upper-atmosphere warming event that led to the smallest ozone hole since the early 1980 s.

Below-average Antarctic sea ice extent persisted throughout 2019, continuing a trend that began in September 2016. Net sea ice extent was below the 1981-2010 average for all days of the year, and January and June each set a new low monthly mean sea ice extent record. The Antarctic ice sheet continued to lose mass, with the highest rates of loss occurring in West Antarctica and Wilkes Land, East Antarctica.

Across the cryosphere, alpine glaciers continued to lose mass for the 32nd consecutive year. Permafrost temperatures in the European Alps were slightly below the record temperatures measured in 2015, while record high permafrost temperatures were observed at a majority of the observation sites across the high northern latitudes. For the first time in the observational record at 26 sites in interior Alaska and the Seward Peninsula, the active layer did not freeze completely, a result of long-term permafrost warming and back-to-back relatively mild and snowy winters.

In March, when Arctic sea ice reached its annual maximum extent, thin, first-year ice comprised $\sim 77 \%$ of all ice, compared to about $55 \%$ in the 1980 s. In September, the minimum sea ice extent tied for the second smallest extent in the 41-year satellite record. In the Bering Sea, increasing ocean temperatures and reduced sea ice-which was the lowest on record there for the second consecutive winter-are leading to shifts in fish distributions within some of the most valuable fisheries in the world. Larger and more abundant boreal species, as opposed to smaller and less abundant Arctic species, dominated a large portion of the Arctic shelf in 2018 and 2019.

During the 2019 melt season, the extent and magnitude of ice loss over the Greenland ice sheet rivaled 2012, the previous year of record ice loss. Melting of glaciers and ice sheets, along with warming oceans, account for the trend in rising global mean sea level.

In 2019, global mean sea level set a new record for the eighth consecutive year, reaching $87.6 \mathrm{~mm}$ above the 1993 average when satellite measurements began, with an annual average increase of $6.1 \mathrm{~mm}$ from 2018. Ocean heat content measured to $700 \mathrm{~m}$ depth was record high, and the globally averaged sea surface temperature was the second highest on record, surpassed only by the record El Niño year of 2016. In October, the Indian Ocean dipole exhibited its greatest magnitude since 1997, associated with dramatic upper ocean warming in the western Indian Ocean basin.

While ENSO conditions during 2019 appeared to have limited impacts, many climate events were influenced by the strong positive IOD, which contributed to a large rainfall deficit from the eastern Indian Ocean to the South Pacific Ocean east of Australia. Record heat and dryness in Australia intensified drought conditions already in place following below-average rainfall in 2017 and 2018, leading to severe impacts during late austral spring and summer, including catastrophic wildfires. 
Smoke from these wildfires, along with the volcanic eruptions of Raikoke (Russia) and Ulawun (Papua New Guinea), helped load the stratosphere with aerosol levels unprecedented since the post-Mt. Pinatubo era of the early 1990s. Indonesia also suffered severe drought and extreme wildfires toward the end of 2019; no rainfall was observed in the East Sumba District of the East Nusa Tenggara Province for 263 days.

Conversely, the positive IOD also contributed to excess rainfall over the Horn of Africa from August through December, resulting in widespread flooding across East Africa. Elsewhere, India experienced one of its heaviest summer monsoon rains since 1995 despite a delayed and suppressed monsoon during June. In the United States, rapid snowmelt in the spring, as well as heavy and frequent precipitation in the first half of the year, contributed to extensive flooding in the Midwest throughout spring and summer, notably the Mississippi and Missouri basins.

Dry conditions persisted over large parts of western South Africa, in some locations having continued for approximately seven years. Antecedent dry conditions and extreme summer heat waves pushed most of Europe into extreme drought.

Due in part to precipitation deficits during December 2018 to January 2019-the peak of the rainy season-wildfires scorched vast areas of the southern Amazonian forests in Bolivia, Brazil, and Peru, as well as in northern Paraguay, later in 2019. Millions of trees and animals perished, with some local extinctions reported. In Siberia, fire activity during the summer was both strong and farther north than usual. This led to a new record of 27 teragrams $\left(10^{12} \mathrm{~g}\right)$ of carbon emitted from fires in the Arctic, which was more than twice as high than in any preceding year.

Closer to the equator, 96 named tropical storms were observed during the Northern and Southern Hemisphere storm seasons, well above the 1981-2010 average of 82. Five tropical cyclones reached Saffir-Simpson scale Category 5 intensity. In the North Atlantic basin, Hurricane Dorian caused unprecedented and tremendous devastation, with over 70 fatalities and damages totaling \$3.4 billion (U.S. dollars) in The Bahamas. Tropical Cyclones Idai and Kenneth severely impacted southeastern Africa in March and April, respectively. Idai resulted in total damages of at least $\$ 2.2$ billion (U.S. dollars), the costliest storm on record for the South Indian Ocean basin, as well as the deadliest with over 1200 fatalities across Mozambique, Zimbabwe, Malawi, and Madagascar. 


\section{STATE OF THE CLIMATE IN 2019}

\section{INTRODUCTION}

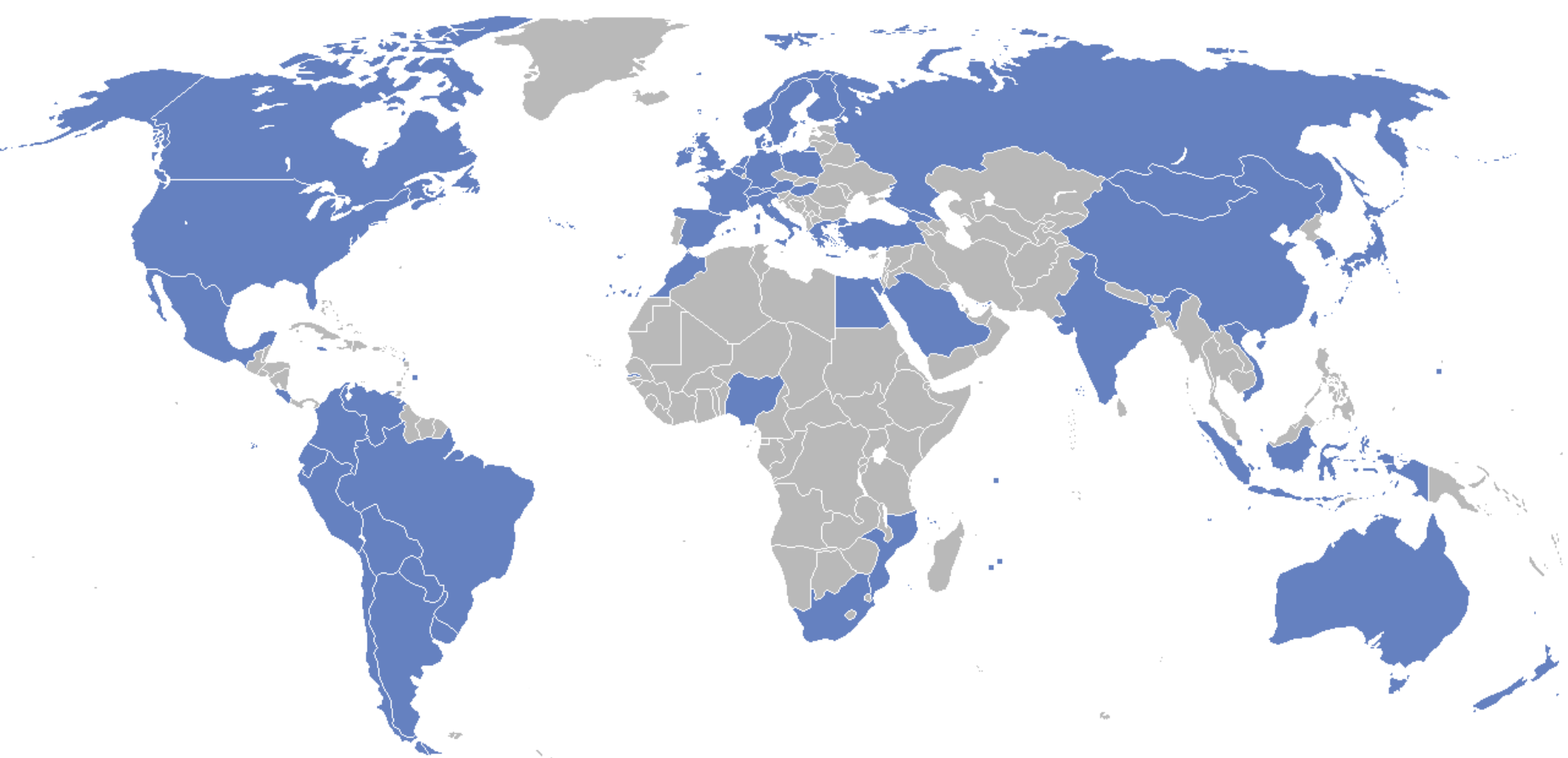

The countries highlighted in blue indicate each of the 61 nations contributing an author and/or chapter editor to the State of the Climate in 2019.

Citing this chapter: Arndt, D. S., J. Blunden, and R. J. H. Dunn. 2020: Introduction [in "State of the Climate in 2019"]. Bull. Amer. Meteor. Soc., 101 (8), S1-S8, https://doi.org/10.1175/2020BAMSStateoftheClimate_Intro.1.

Special Supplement to the Bulletin of the American Meteorological Society, Vol.101, No. 8, August, 2020

The Introduction is one chapter from the State of the Climate in 2019 annual report. Compiled by NOAA's National Centers for Environmental Information, State of the Climate in 2019 is based on contributions from scientists from around the world. It provides a detailed update on global climate indicators, notable weather events, and other data collected by environmental monitoring stations and instruments located on land, water, ice, and in space. The full report is available from https://doi.org/10.1175/2020BAMSStateoftheClimate.1.

https://doi.org/10.1175/2020BAMSStateoftheClimate_Intro.1

Corresponding author, Introduction: Jessica Blunden / jessica.blunden@noaa.gov

(C2020 American Meteorological Society

For information regarding reuse of this content and general copyright information, consult the AMS Copyright Policy. 


\title{
STATE OF THE CLIMATE IN 2019 \\ Introduction
}

\author{
Editors \\ Jessica Blunden \\ Derek S. Arndt

\section{Chapter Editors} \\ Peter Bissolli \\ Howard J. Diamond \\ Matthew L. Druckenmiller \\ Robert J. H. Dunn \\ Catherine Ganter \\ Nadine Gobron \\ Rick Lumpkin \\ Jacqueline A. Richter-Menge \\ Tim Li \\ Ademe Mekonnen \\ Ahira Sánchez-Lugo \\ Ted A. Scambos \\ Carl J. Schreck III \\ Sharon Stammerjohn \\ Diane M. Stanitski \\ Kate M. Willett \\ Technical Editor \\ Andrea Andersen
}

BAMS Special Editor for Climate

Richard Rosen 
Arndt, Derek S., NOAA/NESDIS National Centers for Environmental Information, Asheville, North Carolina

Blunden, Jessica, NOAA/NESDIS National Centers for Environmental Information, Asheville, North Carolina

Dunn, Robert J. H., Met Office Hadley Centre, Exeter, United Kingdom

\section{Editorial and Production Team}

Andersen, Andrea, Technical Editor, Innovative Consulting Management Services, LLC, NOAA/NESDIS National Centers for Environmental Information, Asheville, North Carolina

Griffin, Jessicca, Graphics Support, Cooperative Institute for Satellite Earth System Studies, North Carolina State University, Asheville, North Carolina

Hammer, Gregory, Content Team Lead, Communications and Outreach, NOAA/ NESDIS National Centers for Environmental Information, Asheville, North Carolina

Love-Brotak, S. Elizabeth, Lead Graphics Production, NOAA/NESDIS National Centers for Environmental Information, Asheville, North Carolina
Misch, Deborah J., Graphics Support, Innovative Consulting Management Services, LLC, NOAA/NESDIS National Centers for Environmental Information, Asheville, North Carolina

Riddle, Deborah B., Graphics Support, NOAA/NESDIS National Centers for Environmental Information, Asheville, North Carolina

Veasey, Sara W., Visual Communications Team Lead, Communications and Outreach, NOAA/NESDIS National Centers for Environmental Information, Asheville, North Carolina 


\section{INTRODUCTION—D. S. Arndt, J. Blunden, and R. J. H. Dunn}

This is the 30th edition of what is now known as the State of the Climate report, marking a 30-year period of record for a document that routinely uses 30-year base periods to help contextualize today's climate. Compared to that 30-year record, this 2019 edition is the richest report in the series, well above climatological averages, and indeed setting records for climate variables tracked and for author participation. This year, 528 authors and editors contributed to the report, together representing 61 countries, including for the first time in this series' history authors from the nations of Georgia and Vietnam.

One of the touchpoints of 2019's climate-the Indian Ocean-may turn the globe upside-down for our North American readership. The body of water, cleaved into distinct halves marked by the strongest Indian Ocean Dipole in more than two decades, behaved as something of a center of gravity in this report, as many of the extremes and related phenomena seemed to emanate from it. The strength of its signal was seen throughout the system and throughout this report: in nuisance flooding and unusual chlorophyll concentrations in and around the basin; in unprecedented tropical cyclone activity in the Arabian Sea; as historic fire and drought in Australia; and in back-to-back devastating tropical cyclones in southeast Africa.

In early 2020, our community was likewise turned upside-down, but on a personal level, with the passing of New Zealand's Brett Mullan, himself an accomplished contributor to the understanding of Southern Hemisphere climate and variability, but also a beloved contributor to the Tropics chapter for many years. Its editors have memorialized his contributions and their appreciation in the chapter introduction.

It was also in early 2020 when a global contagion turned upside-down the professional worlds of our many authors and editors, who crafted and shaped their contributions in a much different way, and from much different settings, than anticipated. In an era for which "isolation" took on widespread new contexts, we are forever thankful for the connections among these authors, editors, their expertise, and their dedication to publishing this most comprehensive annual diagnostic of the climate system available.

In service to them, the State of the Climate report has taken several steps to acknowledge the importance of our diverse authorship. The report will now be catalogued as independent chapters, allowing for more full recognition of authorship in the various citation indices. Each of these chapters now has its own cover image, most of which were provided by an author in that very chapter. Finally, the public rollout of this manuscript in the Northern Hemisphere summer of 2020 will consciously attempt to increase awareness of the authors and chapter editors that drive this report.

As is the case every year, several chapter editors have chosen to make adjustments to their chapter's roster and organization of content. This may be to take advantage of analyses made newly available to this report, such as the global lake water levels section and marine heat waves analyzed in Chapter 2; and the polar chapters' commissioning of sections on non-Greenlandic ice in the Arctic, and changes and trends in the Antarctic ice sheet. In some cases, data availability does not allow every-year analysis in this report, requiring occasional appearances. These factors explain the return of the Mauna Loa solar transmission record to the global chapter and the Atlantic Meridional Overturning Circulation to the oceans chapter, and this year's exclusion of Arctic-specific river discharge. 
This year, for the first time in the supplement's 30-year history and in the spirit of minimizing our own impact on climate change, the report is published in digital format only. The general layout, however, remains largely the same. An overview of findings is presented in the Abstract, Fig. 1.1, and Plate 1.1. Chapter 2 features global-scale climate variables; Chapter 3 highlights the global oceans; and Chapter 4 discusses tropical climate phenomena including tropical cyclones. The Arctic and Antarctica respond differently through time and are reported in separate chapters (5 and 6, respectively). Chapter 7 provides a regional perspective authored largely by regional government climate specialists. A list of relevant datasets and their sources for all chapters is provided as an Appendix. Authors, acknowledgments, and references are now listed with each individual chapter.

Time series of major climate indicators are again presented in this introductory chapter. Many of these indicators are essential climate variables, originally defined in GCOS (2003) and updated again by GCOS (2010). As their name indicates, these variables are essential for a full understanding of the changing climate system. However, some of them are not available on the immediate timescales of this report, and others, particularly those dealing with the living world, are outside the scope of this report.

\section{Acknowledgments}

The editors thank the BAMS editorial staff, in particular Bryan Hanssen, who provided technical guidance, oversaw publication of the report, and helped us shepherd the report into a new digital publishing era, Hannah Kleppner, who provided peer review support, and Nicole Rietmann, who oversaw the hundreds of citations and references this year, and the NCEI Graphics team for facilitating the construction of the report and executing the countless number of technical edits needed. We thank our technical editor Andrea Andersen for her dedication and attention to detail. We also express our gratitude to Dr. Rick Rosen, who again served as the AMS special editor for this report. Finally, we thank all of the authors and chapter editors who provide these valuable contributions each year, always with an aim to improve and expand their analyses for the readers. 


\section{Essential Climate Variables—D. S. ARNDT, J. BLUNDEN, AND R. J. H. DUNN}

The following variables are considered fully monitored in this report, in that there are sufficient spatial and temporal data, with peer-reviewed documentation to characterize them on a global scale:

- Surface atmosphere: air pressure, precipitation, temperature, water vapor, wind speed and direction

- Upper atmosphere: Earth radiation budget, temperature, water vapor, wind speed and direction

- Atmospheric composition: carbon dioxide, methane and other greenhouse gases, ozone

- Ocean physics: ocean surface heat flux, sea ice, sea level, surface salinity, sea surface temperature, subsurface salinity, subsurface temperature, surface currents, surface stress

- Ocean biogeochemistry: ocean color

- Ocean biogeosystems: plankton

- Land: albedo, river discharge, snow

The following variables are considered partially monitored, in that there is systematic, rigorous measurement found in this report, but some coverage of the variable in time and space is lacking due to observing limitations or availability of data or authors:

- Atmospheric composition: aerosols properties, cloud properties, precursors of aerosol and ozone

- Ocean physics: subsurface currents

- Ocean biogeochemistry: inorganic carbon

- Land: above-ground biomass, anthropogenic greenhouse gas fluxes, fire, fraction of absorbed photosynthetically active radiation, glaciers, groundwater, ice sheets and ice shelves, lakes, permafrost, soil moisture

The following variables are not yet partially covered in this report, or are outside the scope of it.

- Surface atmosphere: surface radiation budget

- Upper atmosphere: lightning

- Ocean physics: sea state

- Ocean biogeochemistry: nitrous oxide, nutrients, oxygen, transient tracers

- Ocean biogeosystems: marine habitat properties

- Land: anthropogenic water use, land cover, land surface temperature, latent and sensible heat fluxes, leaf area index, soil carbon

Plate 1.1. (next page) Global (or representative) average time series for essential climate variables through 2019. Anomalies are shown relative to the base period in parentheses although base periods used in other sections of the report may differ. The numbers in the square brackets that follow in this caption indicate how many reanalysis (blue), satellite (red), and in situ (black) datasets are used to create each time series in that order. (a) NH polar stratospheric ozone (Mar) $[0,0,1]$; (b) SH polar stratospheric ozone (Oct) [0,0,1]; (c) apparent transmission (Mauna Loa) [0,0,1]; (d) surface temperature [3,0,4]; (e) lower tropospheric temperature [3,2,3]; (f) lower stratospheric temperature [3,3,3]; (g) extremes (warm days (solid) and cool days (dotted)) [0,0,1]; (h) Arctic sea ice extent (max [solid]) and min [dashed]; [0,0,1]); (i) Antarctic sea ice extent (max [solid] and min [dashed]; [0,0,1]); (j) glacier cumulative mean specific balance $[0,0,1]$; $(\mathrm{k}) \mathrm{NH}$ snow cover extent $[0,1,1]$; $(\mathrm{l})$ lower stratospheric water vapor $[0,0,1] ;(\mathrm{m})$ cloudiness $[0,10,0] ;(\mathrm{n})$ total column water vapor - land $[3,1,1] ;(0)$ total column water vapor - ocean $[3,2,0]$; (p) upper tropospheric humidity [1,2,0]; (q) specific humidity - land [4,0,1]; (r) specific humidity - ocean $[4,0,2]$; (s) relative humidity - land [3,0,4]; (t) relative humidity - ocean [3,0,1]; (u) precipitation - land $[0,0,3] ;(v)$ precipitation - ocean $[0,0,1] ;(w)$ ocean heat content $(0-700 \mathrm{~m})[0,0,6] ;(x)$ sea level rise $[0,0,1] ;(y)$ tropospheric ozone $[0,1,0]$; (z) tropospheric wind speed at $850 \mathrm{hPa}$ for $20^{\circ}-40^{\circ} \mathrm{N}$ [4,0,0]; (aa) land wind speed [0,0,1]; (ab) ocean wind speed [3,1,0]; (ac) biomass burning $[0,2,0]$; (ad) soil moisture $[0,1,0]$; (ae) terrestrial groundwater storage $[0,1,0]$; (af) fraction of absorbed photosynthetically active radiation (FAPAR) $[0,1,0]$; (ag) land surface albedo - visible (solid) and infrared (dashed) $[0,1,0]$. 

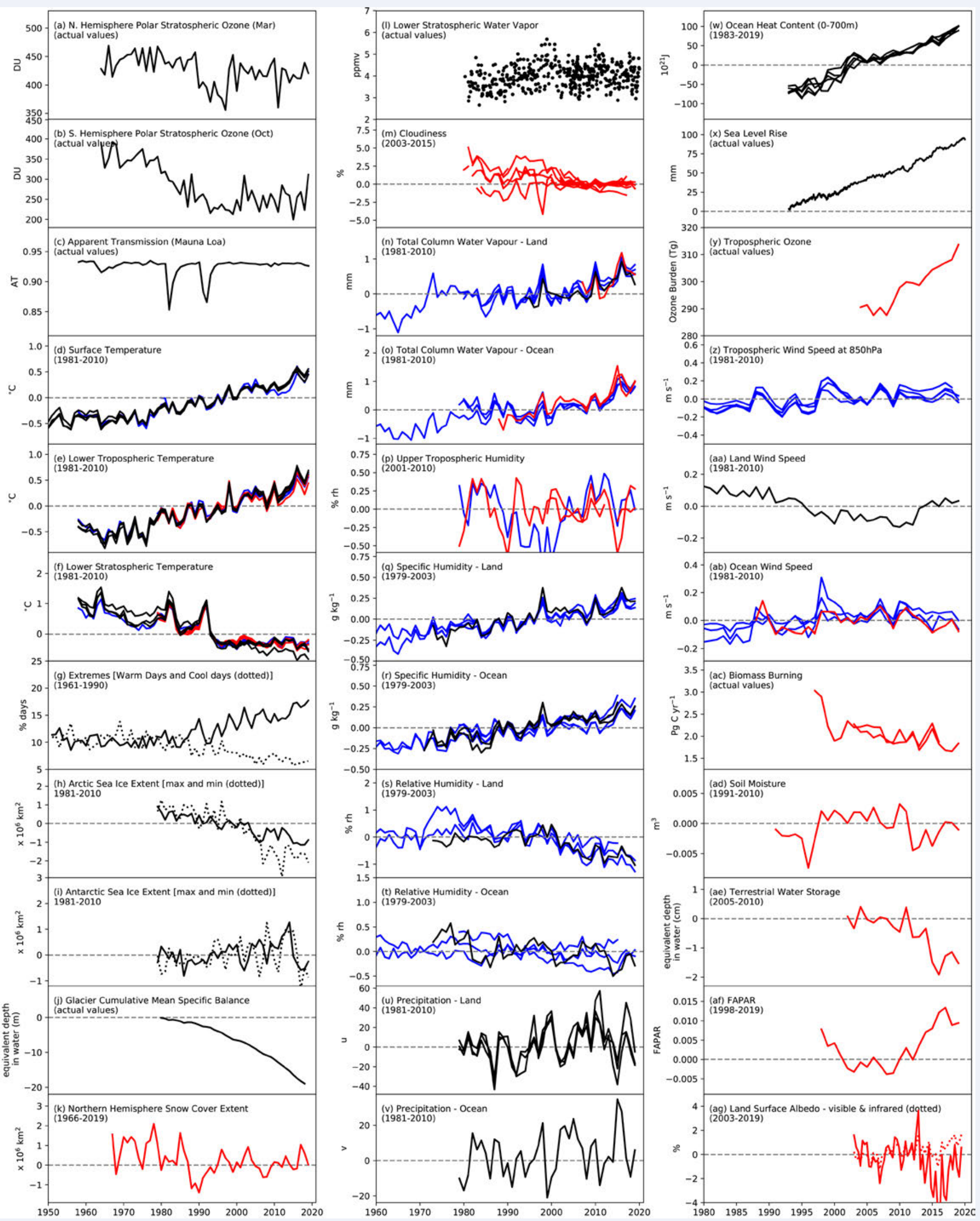


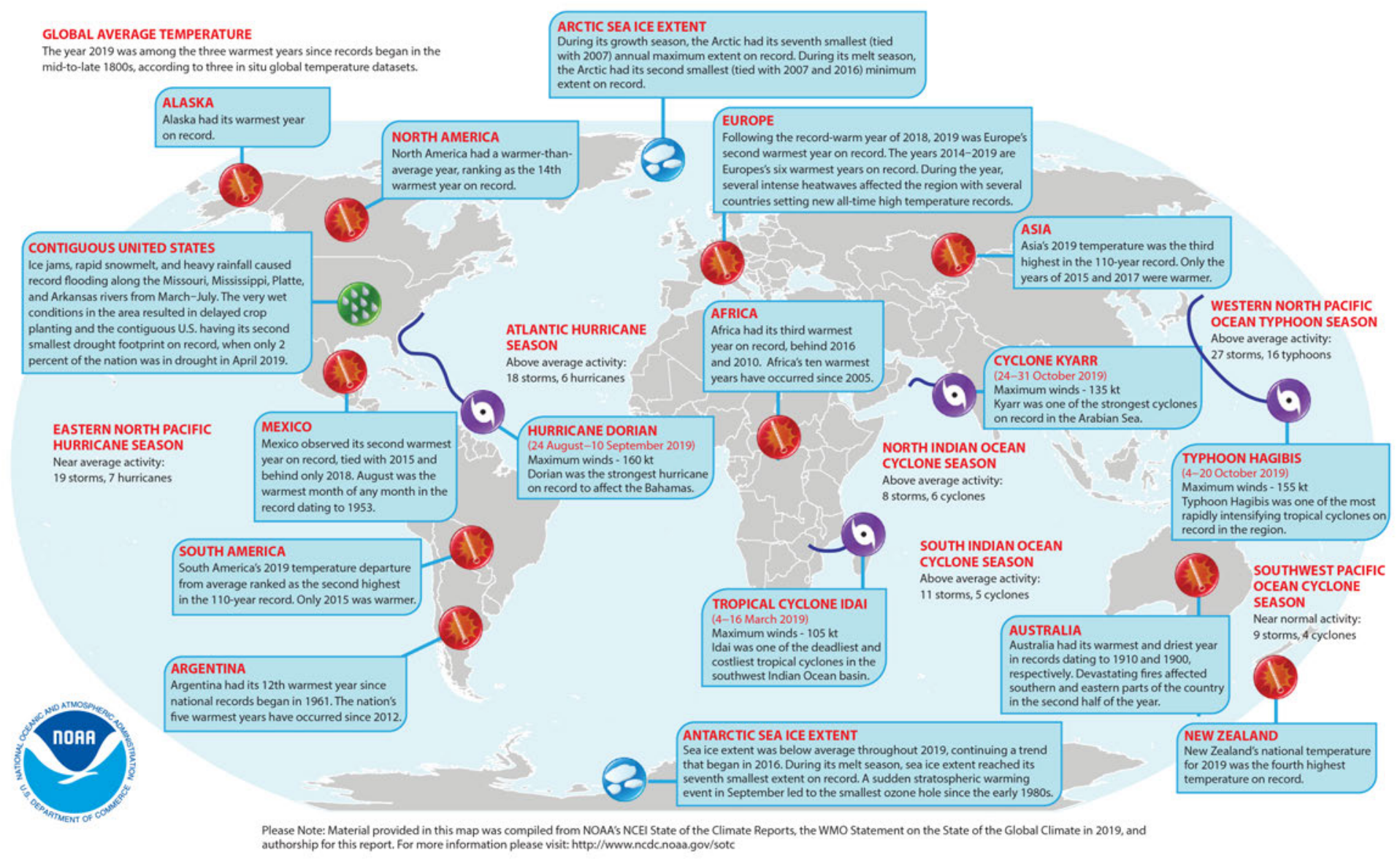

Fig. 1.1. Geographical distribution of selected notable climate anomalies and events in 2019.

\section{References}

GCOS, 2003: The second report on the adequacy of the global observing systems for climate in support of the UNFCCC. GCOS-82 (WMO/TD-1143). World Meteorological Organization, 74 pp., http://www.wmo.int/pages/prog/gcos/Publications/gcos -82_2AR.pdf.
, 2010: Implementation plan for the global observing system for climate in support of the UNFCCC (2010 Update). GCOS-138 (GOOS-184, GTOS-76, WMO/TD-1523). World Meteorological Organization, 180 pp., http://www.wmo.int/pages/prog/gcos/ Publications/gcos-138.pdf. 